\title{
Bone and joint tuberculosis: phthisis changes course
}

\author{
DAVID J. GAWKRODGER* \\ M.B., Ch.B., M.R.C.P. \\ R. B. COLE \\ M.A., M.D. F.R.C.P.
}

The Industrial and Community Health Research Centre, North Staffordshire Medical Institute, Stoke on Trent ST4 7NY

\section{Summary}

Eighteen cases of bone and joint tuberculosis occurred in North Staffordshire between 1976 and 1980. The immigrant population is small and the disease was commonest in whites over 60 years old. There were only three cases of spinal tuberculosis. A lack of uniformity was found in the chemotherapeutic regimens used.

\section{Introduction}

Once a disease is known to be becoming rare, it tends to be forgotten and this may cause diagnostic difficulty. In the United Kingdom this applies to tuberculosis as a whole, the incidence of which continues to decline, and particularly to bone and joint tuberculosis. Our paper, a review of all cases of bone and joint tuberculosis in North Staffordshire over a five-year period, is a reminder that this condition still exists in the United Kingdom, and that it may affect elderly white patients as well as young Asian immigrants.

\section{Materials and methods}

In North Staffordshire, all cases of tuberculosis and all laboratory isolations of mycobacteria are reported to the Shelton Chest Clinic, Stoke-on-Trent, where contact tracing is arranged and information about the patient and his contacts is tabulated. We have studied this data and the hospital notes of all cases of bone and joint tuberculosis reported in the area from 1976 to 1980.

\section{Results}

\section{Incidence and site}

The population of the area has declined to just less than 470,000 of whom about $6,000(1.3 \%)$ are of Asian or African origin. Over the last 10 years there has also been a relative increase in the number of elderly people. In North Staffordshire notifications of

\footnotetext{
*Current address: Department of Dermatology, Royal Infirmary, Edinburgh EH3 9YW.
}

new cases of tuberculosis in the past 5 years have been at a similar level to those in England and Wales (Medical Research Council (MRC) Tuberculosis and Chest Diseases Unit, 1980), but they have been significantly higher for white men and women over 55, and for young Asian females.

Between 1976 and 1980, 18 patients with bone or joint tuberculosis were notified, being $4.3 \%$ of all notifications for tuberculosis in the district (Table 1). The disease was a reactivation of previous infection in four cases. The mean age of the 18 patients was 49.5 years and 10 were 45 years old or over (Table 2 ). The infections were widely distributed throughout the skeleton (Table 3), without any special concentration on the spine.

\begin{tabular}{lc}
$\begin{array}{c}\text { TABLE 1. Distribution of } \mathbf{4 2 2} \text { cases of } \\
\text { tuberculosis in North Staffordshire: }\end{array}$ 1976-80 \\
\hline Site of infection & No. of patients \\
\hline Bone and joint & 18 \\
Other non-pulmonary & 95 \\
Pulmonary & 309 \\
\hline
\end{tabular}

TABLE 2. Age and race of patients with bone and joint tuberculosis

\begin{tabular}{lccccc}
\hline & \multicolumn{5}{c}{ Age (years) } \\
\cline { 2 - 6 } & $0-14$ & $15-44$ & $45-64$ & 65 or more & All ages \\
\hline White & 2 & 2 & 2 & 7 & 13 \\
Asian & 0 & 4 & 1 & 0 & 5 \\
Total & 2 & 6 & 3 & 7 & 18 \\
\hline
\end{tabular}

\section{Predisposing factors}

Four patients had a previous history of joint tuberculosis. Of these, three had presented over 30 years ago and had received no chemotherapy, but one patient had been given streptomycin, isoniazid and para-aminosalicylic acid (PAS) for 2 months, followed by PAS and isoniazid for a further 6 months. Eight years later he presented with a recurrence in the same elbow. Two further patients had the radiological changes of inactive pulmonary 
TABLE 3. Site of disease in 18 patients with bone and joint tuberculosis

\begin{tabular}{lc}
\hline Site of disease & No. of patients \\
\hline Foot & 3 \\
Hip & 3 \\
Vertebra & 3 \\
Ankle & 2 \\
Elbow & 2 \\
Wrist & 2 \\
Humerus & 1 \\
Rib & 1 \\
Shoulder & 1 \\
\hline
\end{tabular}

tuberculosis, for which neither had received treatment, and two had active pulmonary tuberculosis in addition to bone disease. A family history of pulmonary tuberculosis was present in three cases. Radiotherapy for carcinoma of the breast may be a precipitating factor (Guttenberg, 1974; Kaplan, Armstrong and Rosen, 1974), and one such patient developed tuberculous osteomyelitis in the ipsilateral humerus. Trauma to the affected wrist 17 months before presentation may have predisposed another patient to tuberculous arthritis (Stuart, 1976).

\section{Diagnosis}

Of those with peripheral joint disease, seven had a discharging sinus, five had swelling only, two had foot ulcers with local swelling, and the remaining patient presented with pain in the hip without swelling or a sinus. There were three cases of spinal tuberculosis, one of whom had kyphosis, another paraplegia and a third backache.

An average of 5 months elapsed between the onset of symptoms and treatment. Therapy was usually withheld until a diagnosis had been made on microbiological or histological grounds and in only two instances was treatment begun immediately solely on the clinical and radiological findings.

Biopsies were performed in 10 patients and all proved to be positive on histology or culture. Mycobacterium tuberculosis was cultured from biopsy material or the inflammatory exudate in 10 patients, the organism being sensitive to streptomycin, rifam- picin, ethambutol, isoniazid and PAS in all cases. The diagnosis was based on histological criteria in five patients, and solely on radiological appearances in the three others.

\section{Chemotherapy}

The treatment given to the 18 patients is shown on Table 4. One patient died from non-tuberculous causes 2 months after commencing therapy. All seven who completed their course of chemotherapy improved and there have been no relapses. Major surgery was only undertaken for one of the cases of spinal tuberculosis who had a kyphosis and neurological signs in the legs.

\section{Discussion}

Like most forms of tuberculosis, bone and joint disease has a high notification rate among Asian immigrants to the United Kingdom (MRC Tuberculosis and Chest Diseases Unit, 1980; Joint Tuberculosis Committee, 1978). In the series from Brent, an area with a high immigrant population, most patients were Asians under 30 years old (Taor, 1977). Our figures also show a high notification among Asian immigrants, but in this district where the immigrant population is small, bone and joint tuberculosis was found most often in elderly whites. This finding is similar to that of a recent survey in Norway (Pans, 1977).

Spinal tuberculosis occurred in $37 \%$ of patients with bone and joint tuberculosis in the recent national survey (MRC Tuberculosis and Chest Diseases Unit, 1980) and reached 50\% in areas with a high Asian immigrant population (Nicholson, 1974). In contrast, only three (17\%) of the 18 patients from North Staffordshire had spinal tuberculosis; one of these being an Asian. This may reflect the small Asian population in this community.

Bone and joint tuberculosis is especially difficult to diagnose if the radiographs are normal and if no material is available for microbiological examination (Hunt, 1964). One third of our patients had rather non-specific symptoms with local swelling or pain, and here biopsy played an important part in provid-

TABLE 4. Type and duration of chemotherapy in 18 patients with bone and joint tuberculosis

\begin{tabular}{lcccccc}
\hline & \multicolumn{7}{c}{$\begin{array}{c}\text { Duration of chemotherapy } \\
\text { (months) }\end{array}$} \\
Initial drug regimen & $0-5$ & $6-8$ & $9-12$ & $13-18$ & $>18$ & Total \\
\hline Rifampicin, isoniazid, ethambutol* & 1 & 1 & 6 & 3 & 3 & 14 \\
Streptomycin**. PAS $\dagger$, isoniazid & 0 & 1 & 1 & 1 & 1 & 4 \\
All regimens & 1 & 2 & 7 & 4 & 4 & 18 \\
\hline
\end{tabular}

*For initial 6 months (mean).

**For initial 7 months (mean).

$\dagger$ Rifampicin in one case. 
ing material for histology and culture. A high degree of clinical suspicion is needed, as well as early biopsy to speed up diagnosis (Walker, 1968).

Our series highlights a lack of uniformity in the regimens used to treat bone and joint tuberculosis. A similar situation may well exist in other parts of the country, since clinicians seldom see this type of tuberculosis now. Attention has recently been drawn to the occurrence of inadequate drug prescribing for tuberculosis by clinicians who are not chest physicians (Wardman et al., 1982). Most trials of therapy for bone and joint tuberculosis deal only with spinal disease. The Medical Research Council Working Party on tuberculosis of the spine $(1976,1978)$ has shown from trials in Korea, East Africa and Hong Kong, that PAS and isoniazid, given daily for 18 months is effective in $85-90 \%$ of cases whether or not streptomycin is given in addition for the first 3 months. On the other hand, trials of 6 month regimens in Algeria, using daily isoniazid with or without ethionamide or rifampicin, but with daily streptomycin for the first 2 months, led to three failures among 35 spinal cases and one relapse at 2 years among 45 cases of non-spinal osteo-articular disease (Working Group on Bone and Joint Tuberculosis in Algeria, 1979).

These trials may not be fully relevant to treatment in this country because of differences in the age incidence of the disease, the general health of the patients, the facilities for surveillance, and the prevalence of resistant mycobacteria. On theoretical grounds the standard drugs used in Britain for pulmonary tuberculosis may well be equally effective in bone and joint tuberculosis, since both ethambutol and rifampicin readily penetrate tuberculous bone and joint cavities in adequate concentration (Furesz, 1970; Tuli, Kumar and Sen, 1977), and isoniazid diffuses freely into caseous tissue (Barclay et al., 1953). Thus, short courses based on rifampicin which are successful in pulmonary tuberculosis (British Thoracic and Tuberculosis Association, 1976) should also be effective in the osteo-articular lesions, which contain fewer bacilli than those in the lung (Canetti, Debeyre and De Sèze, 1957). At present, we prefer either to use the MRC regimen for 18 months or, to administer a 9-month course of isoniazid and rifampicin plus ethambutol for the first 2 months - as used in this country for pulmonary tuberculosis, and then to follow up all treated cases for 5 years. This prolonged surveillance is feasible because of the small number of cases which occur in the United Kingdom.

The recent survey in England and Wales (MRC Tuberculosis and Chest Diseases Unit, 1980) identified 163 new cases of bone and joint tuberculosis, and this was second only to lymph node tuberculosis among the sites of non-respiratory disease. Our own experience suggests that this type of tuberculosis is not declining as rapidly as is pulmonary disease (Table 1), and it is therefore important to devise the best regimen for its treatment; this objective could most readily be achieved by a multicentre trial.

\section{Acknowledgments}

We are grateful to Dr N. W. Horne, Mr W. M. Steel and Mr J. Dove for their help in the preparation of this paper.

\section{References}

Barclay, W.R., Ebert, R.H., Le Roy, G.V., Manthei, R.W. \& RoTH, L.J. (1953) Distribution and excretion of radioactive isoniazid in tuberculous patients. Journal of American Medical Association, 151, 1384.

British ThORACIC AND Tuberculosis Association (1976) Short course chemotherapy in pulmonary tuberculosis. Lancet, ii, 1102.

Canetti, G., Debeyre, J. \& De Séze, S. (1957) Stérilisation des lésions de la tuberculose ostéo-articulaire par la chimiothérapie antibacillaire. Revue de la Tuberculose (Paris), 21, 1337.

FURESZ, S. (1970) Chemical and biological properties of rifampicin. Antibiotics and Chemotherapy, 16, 316.

GUTTENBERG, S.A. (1974) Osteoradionecrosis of the jaw. American Journal of Surgery, 127, 326.

HUNT, D.P. (1964) Problems in diagnosing osteoarticular tuberculosis. Journal of the American Medical Association, 190, 95.

JoINT TUBERCulosis CoMmitTeE (1978) Tuberculosis among immigrants in Britain. British Medical Journal, 1, 1038.

Kaplan, M.H., ARmstrong, D. \& Rosen, P. (1974) Tuberculosis complicating neoplastic disease. Cancer, 33, 850.

Medical Research Council Tuberculosis and Chest Disease UNIT (1980) National survey of tuberculosis notifications in England and Wales 1978-9. British Medical Journal, 2, 895.

MEDICAl RESEARCh COUNCIL WORKING PARTY ON TUBERCULOSIS OF THE SPINE (1976) A 5-year assessment of controlled trials of in patient and out patient treatment and of plaster of paris jackets for tuberculosis of the spine in children on standard chemotherapy. Journal of Bone and Joint Surgery, 58B, 399.

Medical Research Council Working Party on Tuberculosis OF THE SPINE (1978) 5-year assessments of controlled trials of ambulatory treatment, debridement and anterior spinal fusion in the management of tuberculosis of the spine. Journal of Bone and Joint Surgery, 60B, 163.

Nicholson, R.A. (1974) Twenty years of bone and joint tuberculosis in Bradford. Journal of Bone and Joint Surgery, 56B, 760.

PANS, B. (1977) The changed pattern of bone and joint tuberculosis in Norway. Acta orthopaedica Scandinavica, 48, 277.

STUART, D. (1976) Local osteoarticular tuberculosis complicating closed fractures. Journal of Bone and Joint Surgery, 58B, 248.

TAOR, W.S. (1977) Bone and joint tuberculosis in Brent. In: Symposium on extra pulmonary tuberculosis, p. 1. Royal Society of Medicine, London.

TULI, S.M., KUMAR, K. \& SEN, P.C. (1977) Penetration of antitubercular drugs in clinical osteoarticular tubercular lesions. Acta orthopaedica Scandinavica, 48, 362.

WALKER, G.F. (1968) Failure of early recognition of skeletal tuberculosis. British Medical Journal, 1, 682.

Wardman, A.G., Williams, S.E., Curzon, P.G.D., Page, R.L. \& COOKE, N.J. (1982) Tuberculosis: who should prescribe? British Medical Journal, 1, 569.

WORKING GROUP ON BONE AND JOINT TUBERCULOSIS IN ALGERIA (1979) Short course chemotherapy in bone and joint tuberculosis-therapeutic trial comparing three short course regimens (preliminary report). Bulletin of the International Union against Tuberculosis, 54, 19. 